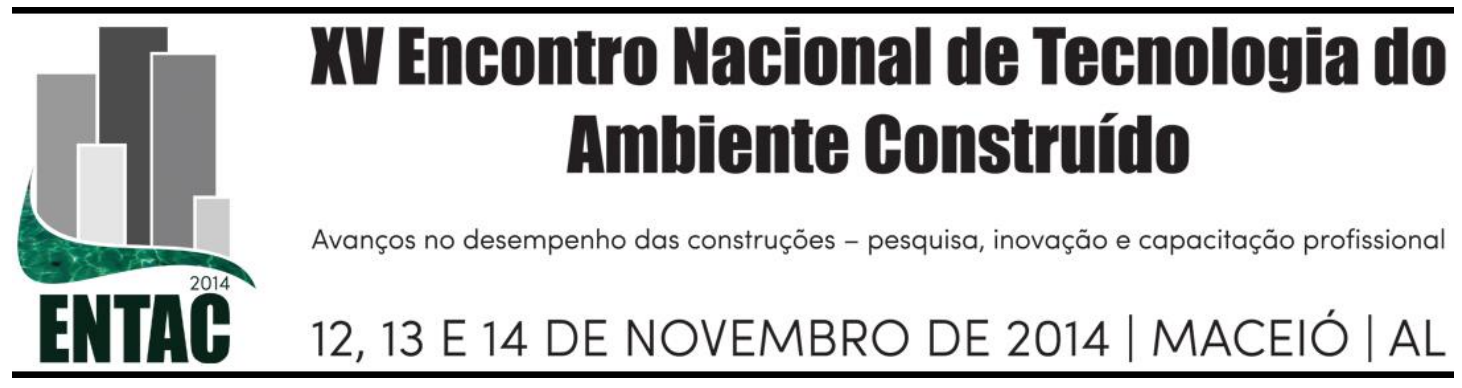

\title{
INVESTIGAÇÃO DE METODOLOGIAS PARA SIMULAÇÃO DE DESEMPENHO DA ILUMINAÇÃO ARTIFICIAL COM A PRESENÇA DE PROTEÇÃO SOLAR EM EDIFÍCIOS RESIDENCIAIS
}

\author{
SOARES, Carla Patrícia Santos (1); LEMOS, Raquel Duarte (2); SOUZA, \\ Roberta Vieira Gonçalves (3); \\ (1) UFMG, 31 8791-3395, pati.incd@ gmail.com (2) UFMG, 31 9126-7368, queldl25@ gmail.com; (3) \\ UFMG, 31 3409-8822, roberta@arq.ufmg.br
}

\begin{abstract}
RESUMO
Em países tropicais, como o Brasil, a iluminação natural é um recurso utilizado para reduzir o consumo de energia das edificações, porém seu uso indiscriminado pode resultar em situações como ofuscamento ou aquecimento excessivo do ambiente. Para prevenir essas situações indesejadas e permitir a integração da luz natural ao ambiente, os dispositivos de proteção solar apresentam-se como importante alternativa. O Regulamento Técnico da Qualidade para o Nível de Eficiência Energética em Edificações Residenciais (RTQ-R) considera esses dispositivos pelo seu efeito no comportamento térmico dos edifícios, desconsiderando o consumo de energia por iluminação artificial devido à sua presença $\mathrm{A}$ fím de se observar esta questão, foi feita uma investigação do desempenho termoenergético e lumínico de ambientes quando usados diferentes dispositivos de proteção solar. Foram feitas simulações nos softwares Daysim e EnergyPlus para se obter dados quantitativos de acionamento e consumo da iluminação artificial e de desempenho térmico. Este artigo monstra o processo de escolha entre os tipos de acionamento de iluminação artificial do software Daysim 3.1 para se determinar o sistema que melhor identifica a necessidade de acionamento da iluminação artificial em ambientes residenciais com dispositivos de proteção. Os sistemas estudados foram o "switch off occupancy sensor" e o "combination on/off occupancy and dimming system", denominados "sensor-usuário" e "sensor-automatizado", respectivamente. O sensor-usuário é acionado pelo ocupante enquanto o sensor-automatizado é controlado apenas por sensores de ocupação e iluminância. Os resultados mostraram que, apesar de o sensor-usuário apresentar uma situação mais próxima do comportamento de um usuário real, o sensorautomatizado permite uma análise mais precisa da necessidade de acionamento da iluminação artificial no ambiente interno. Isso foi evidenciado pela maior variação entre o aumento do consumo de energia dos ambientes com dispositivos de sombreamento, em relação ao modelo sem proteção solar, para ambientes com sensor-automatizado em relação aos ambientes nos quais se usou o sensor-usuário.
\end{abstract}

Palavras-chave: Iluminação artificial, eficiência energética, Daysim, RTQ-R

\begin{abstract}
In tropical countries, such as Brazil, daylight is an important feature used to reduce energy consumption in buildings. However its indiscriminate use may result in situations such as glare and excessive heating of the room. To prevent such unwanted situations and allow natural light in the room, shading devices appear as an important strategy. The Brazilian Regulation for Energy Efficiency of Residential Buildings $(R T Q-R)$ considers shading devices by their effect on the thermal behavior of buildings, not taking into account the artificial lighting energy consumption caused by their presence. In order to study this issue, a thermo energetic behavior investigation was conducted for rooms with different shading devices. Simulations were performed in Daysim and EnergyPlus to get quantitative data about artificial lighting activation and the room's energy consumption and thermal performance. This article shows the choosing process between the artificial lighting activation systems available in Daysim 3.1, to determine the best
\end{abstract}


one to evaluate artificial lighting activation in residential rooms with shading devices. The studied systems are "switch off occupancy sensor" and "combination on/off occupancy and dimming system" which were named in this study "user-sensor" and "automatic-sensor", respectively. The automaticsensor is controlled only by occupancy and illuminance sensors while the user-sensor is activated by the user. The results showed that, although the user-sensor demonstrates a situation closer to a real user, the automated-sensor allows a more accurate view of the need of artificial lighting activation. This was evidenced by the greater variance between the increase in energy consumption of rooms with shading devices, in comparison with the model without solar shading, for the automatic-sensor in regard to the user-sensor.

Keywords: artificial lighting, energy efficiency, Daysim, RTQ-R.

\section{INTRODUÇÃO}

O desenvolvimento deste artigo foi apoiado, por meio de bolsas de pesquisador, pelo projeto de pesquisa CIE (Convênio ${ }^{\circ}$ ECV DTP 002/2011) que pretende incentivar o desenvolvimento de pesquisas da área de iluminação natural para colaboração com a etiquetagem de eficiência energética de edificações.

Após anos de uso intenso e indiscriminado da energia pelo homem surgiram crises provenientes da escassez dos recursos, como a crise do petróleo na década de 70 , que afetou a economia mundial e despertou olhares para outras fontes de energia No Brasil, a crise energética de 2001, provocou o racionamento de energia, abalando a economia e a cultura de consumo do país (BRASIL, 2012). Como importante medida governamental brasileira de eficiência energética foram lançados, em 2009, o Regulamento Técnico da Qualidade para o Nível de Eficiência Energética de Edifícios Comerciais, de Serviços e Públicos, o RTQ-C, e, em 2010, regulamento de Edificações Residenciais, o RTQ-R (BRASIL, 2010; BRASIL, 2012). Estes regulamentos visam estipular referências quanto ao desempenho energético das edificações a partir de valores e métodos comparativos para classificar a edificação como mais eficiente (nota A) ou menos eficiente (nota E) em relação ao consumo de energia.

$\mathrm{O}$ recente interesse pelas questões de eficiência energética e de qualidade e conforto ambiental em edifícios estimulou um retorno ao uso da luz natural (ROAF, 2009). Contudo, a admissão indiscriminada da luz natural em ambientes localizados em climas quentes favorece situações desagradáveis de ofuscamento ou de acúmulo de cargas térmicas oriundas da insolação. Tais situações resultam em soluções imediatistas de bloqueio da luz solar, impedindo a entrada de luz natural no ambiente (BOGO 2009). Neste contexto, os dispositivos de proteção solar são importantes ferramentas para evitar essas situações desconfortáveis e a integração da luz natural ao ambiente. Porém, estes dispositivos devem ser pensados tanto em relação ao conforto térmico do ambiente como quanto à disponibilidade de luz natural neste.

No RTQ-R, a presença de dispositivos de proteção solar nas aberturas, considerada na avaliação da envoltória da edificação, é definida pela variável somb. Sua pontuação varia de 0 (zero) a 1 (um), sendo 0 para aberturas sem proteção solar e 1 apenas quando utilizadas venezianas. Outros dispositivos, como brises, beirais e varandas, são pontuados a partir de dois outros métodos, podendo receber pontuações de até 0,5 (BRASIL, 2012). Assim, dispositivos diferentes de venezianas não alcançam a pontuação máxima, ainda que possam apresentar efetivo sombreamento no período de insolação. Isso acontece porque o Regulamento considera os dispositivos de proteção solar apenas em relação ao conforto térmico do ambiente, não levando em conta o escurecimento causado pela sua presença.

Neste contexto, Soares (2014) desenvolveu um estudo a fim de contribuir para o aperfeiçoamento da avaliação do uso de dispositivos de proteção solar em edificações residenciais pelo RTQ-R, dentro do projeto da CIE-BRASIL que visa o aprimoramento 
das questões de iluminação natural nos dos regulamentos de eficiência energética. $\mathrm{O}$ estudo investigou a influência de diferentes dispositivos de proteção solar no comportamento térmico, luminoso e energético de ambientes residenciais, considerando o contexto brasileiro, por meio de simulações computacionais. A fim de se definir a influência do uso dos dispositivos de proteção solar quanto à iluminação do ambiente foram feitas simulações no software Daysim. Para tanto, surgiu a necessidade de se fazer um estudo aprofundado em relação aos diferentes modelos de acionamento do software para se determinar qual deles melhor atenderia ao objetivo da pesquisa. Este artigo apresenta uma discussão acerca do processo de análise e escolha do modo de acionamento da iluminação artificial usado nas simulações de Soares (2014) para investigação do impacto do uso de dispositivos de proteção solar em edificações residenciais.

\section{REVISÃO BIBLIOGRÁFICA}

O uso da luz natural nos ambientes internos traz diversos benefícios. Além da disponibilidade durante grande parte do dia, do excelente índice de reprodução de cor e da possibilidade de altos índices de iluminação no ambiente interno, pode reduzir o consumo de energia elétrica para iluminação artificial (CORBELLA e YANNAS, 2003). Neste contexto, os elementos de proteção solar são uma alternativa para admitir a luz natural no ambiente de forma a garantir adequados níveis de iluminação, mas controlando ganhos de calor. A importância do uso de dispositivo de sombreamento em aberturas para a melhoria do conforto térmico interno tem sido demonstrada em pesquisas recentes, como a de Sorgato, Versage e Lamberts (2011). Nesta, foram realizadas simulações computacionais de um dormitório em uma edificação residencial com e sem venezianas horizontais, para quatro orientações solares diferentes. Os resultados demonstraram que os dormitórios sem venezianas, para as fachadas norte e sul, apresentaram, em média, somatório de graus-hora de resfriamento (GHR) 32\% maior que os ambientes com dispositivo de sombreamento. Já para oeste e leste, o aumento de GHR foi de $82 \%$ e $47 \%$, respectivamente.

Um estudo realizado por Didoné e Bittencourt (2008) sobre o impacto causado pela ausência e pelo uso de dispositivos de proteção solar no consumo de energia elétrica em edificações hoteleiras adotou modelos arquitetônicos já construídos, mas que não eram adequados ao clima investigado. Foi possível observar com a inserção dos dispositivos de proteção solar que estes impediram a passagem da radiação solar direta e alcançaram uma redução no consumo de energia de $2 \%$ a $6 \%$ referente ao uso do sistema de arcondicionado. Além disso, as alterações na configuração arquitetônica promoveram um eficiente desempenho lumínico no interior dos quartos.

Cintra (2011), em seu trabalho de dissertação, investigou a influência da profundidade na autonomia de luz natural do ambiente, para aberturas com e sem proteção solar. Os estudos foram realizados para edificações residenciais e para todas as orientações solares, em 11 cidades brasileiras, por meio de simulações computacionais realizadas no software Daysim. A autora concluiu que, para as condições de seu estudo, a profundidade limite do ambiente sem proteção solar deve ser 2,6 vezes a altura da janela, enquanto para o ambiente com proteção solar este valor deve ser de 2,1 vezes no máximo, ou seja, uma redução de $17,9 \%$ em relação a ambientes sem proteção solar. Deste modo, conclui-se que a presença de dispositivos de proteção solar diminui a autonomia de luz natural do ambiente. Sendo assim, pode-se notar que os dispositivos de proteção solar provocam um escurecimento no ambiente fazendo com que o usuário acione a iluminação artificial com maior frequência. 
O software Daysim é uma ferramenta utilizada para simular a integração de sistemas de iluminação artificial com a luz natural. Para investigar o comportamento do usuário em relação ao acionamento da iluminação artificial e das persianas foi criado o Lightswitch, um algoritmo comportamental publicado no estudo de Reinhart (2004) e integrado ao Daysim. Este algoritmo busca predizer as ações dos usuários sobre os sistemas de controle de iluminação artificial e de proteção solar do tipo persiana e foi desenvolvido a partir de observações comportamentais dos usuários por meio de pesquisas de campo realizadas em escritórios ocupados por uma ou duas pessoas. A partir das observações e de análises probabilísticas, o autor determinou seis tipos de acionamento da iluminação artificial, que variam de acordo com o tipo de acionamento do sistema (manual ou automatizado) e o modo de funcionamento do mesmo (on/off ou dimerizável).

\section{METODOLOGIA}

O desenvolvimento deste estudo foi dividido em quatro etapas sendo a primeira a escolha dos sistemas de iluminação artificial a serem investigados por simulação computacional, a segunda, a escolha dos ambientes e, por fim, as simulações computacionais de iluminação e de consumo de energia.

Com intuito de se investigar os sistemas de iluminação artificial em ambientes residenciais procurou-se identificar sistemas que se adequassem à realidade da tipologia escolhida. Sendo assim, dentre os modelos disponíveis no Daysim 3.1, buscou-se sistemas que simulariam um comportamento de acionamento on/off, tipologia mais comum em edificações residenciais. Foi necessária uma investigação destes sistemas uma vez que o acionamento da iluminação artificial do Daysim foi idealizado a partir de pesquisas de campo feitas em ambientes de escritórios.

Primeiramente, os modelos foram divididos em dois grupos: aqueles acionados manualmente e os acionados automaticamente. A seguir, foi escolhido um sistema de cada grupo, baseado em suas características principais, para ser analisado por simulação computacional. Por fim, foram feitas as simulações para se determinar qual tipo de acionamento, o automatizado ou o manual, e qual dos sistemas seria melhor para verificar a necessidade de acionamento da iluminação artificial em ambientes residenciais com dispositivos de proteção solar.

Os modelos utilizados para as simulações foram aqueles definidos por Soares (2014), conforme descrito a seguir. Foram simulados os ambientes de estar e dormitório de um pavimento intermediário de uma edificação multifamiliar, para quatro orientações solares (norte, sul, leste e oeste) e para a cidade de Florianópolis (representante da Zona Bioclimática 3). A fim de se avaliar o desempenho dos elementos de proteção solar em relação ao controle da insolação direta e à disponibilidade de luz natural, foi pensada uma ocupação constante nos ambientes simulados. Para definição do sistema de iluminação artificial, foi feito um projeto luminotécnico, resultando no uso de duas luminárias para o ambiente de estar e uma luminária para o dormitório. As áreas de janelas foram definidas de acordo com o padrão definido por Guedes (2012) como recorrente em edificações residenciais (15\% da área do piso para o dormitório e $25 \%$ da área do piso para o estar). Por fim, foram selecionados dispositivos de proteção solar para serem comparados aos referenciados pelo RTQ-R (Tabela 1).

Tabela 1 - Dispositivos de proteção solar

\begin{tabular}{c|c|l}
\hline Modelo & Tipologia & \multicolumn{1}{|c}{ Descrição } \\
\hline & Sem Proteção (SP) & $\begin{array}{l}\text { Modelo sem dispositivo de proteção solar } \\
\text { (pontuação 0 no RTQ-R), base de comparação para } \\
\text { o desempenho dos dispositivos de proteção }\end{array}$ \\
\hline
\end{tabular}




\begin{tabular}{|c|c|c|}
\hline $\begin{array}{l}\text { Veneziana } \\
\text { fechada }\end{array}$ & $\begin{array}{c}\text { Veneziana externa definida de } \\
\text { acordo com o modelo adotado } \\
\text { para a elaboração do RTQ-R } \\
\text { (VRTQR) }\end{array}$ & $\begin{array}{l}\text { Veneziana externa definida de acordo com o } \\
\text { modelo do RTQ-R: sempre fechada para ZB } 6 \text { a } 8 \\
\text { e fechada na primavera e verão e aberta durante o } \\
\text { outono e o inverno para ZB } 1 \text { a } 4\end{array}$ \\
\hline & $\begin{array}{l}\text { Veneziana com abertura } \\
\text { completa da área (V90) }\end{array}$ & $\begin{array}{l}\text { Veneziana externa com quatro folhas sendo, duas } \\
\text { compostas por venezianas e duas envidraçadas. } \\
\text { Simula o comportamento de venezianas que } \\
\text { podem ser abertas totalmente }\end{array}$ \\
\hline & $\begin{array}{c}\text { Veneziana com abertura de até } \\
45 \% \text { da área (V45) }\end{array}$ & $\begin{array}{l}\text { Veneziana externa com envidraçamento de apenas } \\
45 \% \text { do vão da abertura, uma vez que possui três } \\
\text { folhas, duas compostas por venezianas e uma } \\
\text { envidraçada }\end{array}$ \\
\hline & $\begin{array}{l}\text { Dispositivos de proteção solar } \\
\text { definidos pelo método das } \\
\text { latitudes do RTQ-R (L23) }\end{array}$ & $\begin{array}{l}\text { Protótipo baseado no texto do RTQ-R que objetiva } \\
\text { uma maneira simplificada de mensurar o } \\
\text { sombreamento realizado por varandas, beirais e } \\
\text { brises horizontais }\end{array}$ \\
\hline & $\begin{array}{l}\text { Dispositivos de proteção solar } \\
\text { segundo o método do Anexo } 1 \\
\text { do RTQ-R (TN) }\end{array}$ & $\begin{array}{l}\text { Protótipo definido a partir do dimensionamento } \\
\text { das proteções pelo método de avaliação do Anexo } \\
1 \text { do RTQ-R }\end{array}$ \\
\hline & $\begin{array}{l}\text { Dispositivo de proteção solar } \\
\text { com sombreamento durante o } \\
\text { período de disponibilidade de } \\
\text { luz natural útil - Placa inteira } \\
\qquad \text { (PTI) }\end{array}$ & $\begin{array}{l}\text { Protótipo idealizado com a previsão de } \\
\text { sombreamento durante o período de } \\
\text { disponibilidade de luz natural útil (Guedes, } 2012^{1} \text { ): } \\
\text { das } 7 \mathrm{~h} 40 \text { às } 16 \mathrm{~h} 20 \text {. Formado por composição de } \\
\text { placas inteiras horizontais e verticais }\end{array}$ \\
\hline & $\begin{array}{l}\text { Dispositivo de proteção solar } \\
\text { com sombreamento durante o } \\
\text { período de disponibilidade de } \\
\text { luz natural útil) - Placas } \\
\quad \text { filetadas (PTF) }\end{array}$ & $\begin{array}{l}\text { Protótipo caracterizado da mesma forma que o } \\
\text { anterior, mas com placas filetadas, para investigar } \\
\text { a influência da forma do dispositivo e o impacto de } \\
\text { maiores superfícies refletivas no desempenho } \\
\text { térmico e luminoso }\end{array}$ \\
\hline
\end{tabular}

Com os modelos definidos, as simulações foram realizadas no software Daysim. O programa produz um relatório com valores métricos para cada ponto de uma malha de sensores adotada. Neste estudo, utilizou-se a métrica de Autonomia de Luz Natural (Dayligth Autonomy) para verificar quando a iluminação artificial seria acionada, baseado no nível mínimo de iluminância proveniente da luz natural exigido pela NBR 5413 (ABNT, 2013) - 100 lux para ambientes de estar e dormitório. A malha de sensor foi localizada de acordo com o projeto luminotécnico, a fim de se verificar a

Figura 1 - Localização dos sensores

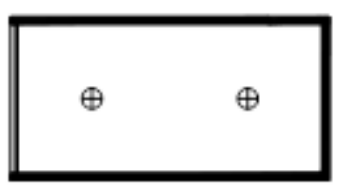

Estar

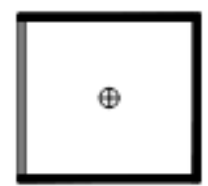

Dormitório necessidade ou não do acionamento das luminárias. Para o ambiente de dormitório, foi utilizado apenas um sensor, localizado no centro do ambiente e a $0,75 \mathrm{~cm}$ de altura do piso, enquanto para o ambiente de estar foram utilizados dois sensores localizados no eixo longitudinal central do ambiente, à mesma altura (Figura 1).

A rotina de acionamento das venezianas V90 e V45 foi definida pelo modelo de sombreamento dinâmico do Daysim, o qual prevê fechamento quando há um brilho

\footnotetext{
${ }^{1}$ Guedes definiu o período de disponibilidade de luz natural útil a partir do requisito do RTQ-R que exige a comprovação do nível de iluminância mínimo no ambiente durante $70 \%$ das horas com luz natural no ano. A autora considerou o horário de $6 \mathrm{~h} 00$ as $18 \mathrm{~h} 00$ como horário de duração média do dia e selecionou $70 \%$ deste horário, resultando no período de $7 \mathrm{~h} 45$ as $16 \mathrm{~h} 15$.
} 
excessivo no plano de trabalho ou quando há valores de insolação direta acima de $50 \mathrm{~W} / \mathrm{m}^{2}$. Os sensores que preveem este acionamento foram alocados juntos aos sensores do sistema de iluminação. Para o modelo de veneziana VRTQR a rotina de acionamento foi definida de acordo com a época do ano, conforme exposto na Tabela 1. Já os modelos de sombreamento estático como L23, TN, PTI e PTF foram definidos como parte do modelo 3D incorporado ao edifício. Os resultados de acionamento gerados pelo Daysim foram usados como dado de entrada no EnergyPlus, de forma a se obter resultados relativos ao consumo de energia.

\section{ANÁLISE E DISCUSSÃO DOS RESULTADOS}

\subsection{Seleção dos sistemas para simulações teste}

A partir do estudo desenvolvido por Reinhart (2004) relativo à comparação do consumo de energia do sistema de iluminação artificial entre diferentes tipos de usuários e modelos de acionamento, foram identificadas as principais características dos modelos de acionamento da iluminação artificial do algoritmo Lightswitch do Daysim 3.1. Estas características foram tabuladas na Tabela 2.

Tabela 2 - Modelos de acionamento da iluminação artificial do Daysim 3.1

\begin{tabular}{l|l}
\hline \multicolumn{1}{c|}{ Modelo } & \multicolumn{1}{c}{ Descrição } \\
\hline $\begin{array}{l}\text { Manual on/off } \\
\text { near the door }\end{array}$ & $\begin{array}{l}\text { Acionamento típico de interruptor manual (on/off) próximo a porta. O } \\
\text { usuário aciona o sistema uma vez ao dia, quando o nível de iluminância no } \\
\text { ambiente é insuficiente, e permanece com o sistema acionado durante o } \\
\text { restante do período de ocupação, desligando-o ao deixar o escritório }\end{array}$ \\
\hline $\begin{array}{l}\text { Switch off } \\
\text { occupancy sensor }\end{array}$ & $\begin{array}{l}\text { Considera o acionamento do sistema pelo usuário como no modelo manual } \\
\text { acima, mas com desligamento automatizado por sensor de presença }\end{array}$ \\
\hline $\begin{array}{l}\text { Switch on/off } \\
\text { occupancy sensor }\end{array}$ & $\begin{array}{l}\text { Modelo automatizado que vincula o acionamento e o desligamento do } \\
\text { sistema de iluminação à ocupação do ambiente, por meio de um sensor de } \\
\text { presença. }\end{array}$ \\
\hline $\begin{array}{l}\text { Photosensor } \\
\text { controlled } \\
\text { dimming system }\end{array}$ & $\begin{array}{l}\text { Modelo cujo acionamento se dá como no modelo manual, porém é } \\
\text { dimerizável, ou seja, complementa o nível de iluminância fornecido pela } \\
\text { luz natural. Neste modelo é previsto que o usuário, às vezes, esquece } \\
\text { sistema acionado ao deixar o ambiente. Isso porque considera que, } \\
\text { dependendo da intensidade da iluminação natural quando o usuário deixa o } \\
\text { escritório, ele não percebe que o sistema artificial está ativado, deixando-o } \\
\text { ativado durante toda a noite }\end{array}$ \\
\hline $\begin{array}{l}\text { Combination } \\
\text { switch off } \\
\text { occupancy and } \\
\text { dimming sensor }\end{array}$ & $\begin{array}{l}\text { Considera o acionamento inicial manual pelo usuário ao ocupar o } \\
\text { ambiente, porém com uma ativação dimerizável do sistema por } \\
\text { fotossensor e o desligamento automatizado por sensor de presença. Assim, } \\
\text { o sistema dimerizável só fica disponível quando o interruptor está } \\
\text { acionado }\end{array}$ \\
\hline $\begin{array}{l}\text { Combination } \\
\text { on/off occupancy } \\
\text { and dimming } \\
\text { system }\end{array}$ & $\begin{array}{l}\text { Modelo automatizado que vincula o acionamento e desligamento do } \\
\text { sistema de iluminação artificial à ocupação do ambiente, porém com } \\
\text { ativação dimerizável do sistema por fotossensor. Assim, o sistema fica } \\
\text { disponível para dimerização durante todo o período de ocupação }\end{array}$ \\
\hline
\end{tabular}

Posteriormente, os modelos foram divididos em dois grupos: o de sistemas que simulam o comportamento de um acionamento manual e os que simulam um comportamento automatizado (Tabela 2). Um sistema de cada grupo foi escolhido para ser conduzido às simulações teste, de forma a identificar qual tipo seria adequado para investigação do impacto do uso de elementos de proteção solar sobre a iluminação do ambiente. 
No grupo que representa a tipologia de acionamento manual, o modelo manual on/off near the door é acionado de acordo com o comportamento do usuário, que muitas vezes não considera o nível de iluminância interno, não sendo indicado para este tipo de simulação. O photosensor controlled dimming system não se adequou à proposta, pois considera um esquecimento eventual por parte do usuário, como mostrado na Tabela 2, identificado como rotineiro pela pesquisa de Reinhart (2004). Sendo assim, este modelo não permite uma investigação da real necessidade de utilização do sistema de iluminação artificial. O modelo combination switch off occupancy and dimming system foi descartado pois, apesar de considerar o comportamento do usuário quanto ao acionamento inicial do sistema, a iluminação é ativada de maneira dimerizada. Sendo assim, não representa um acionamento on/off, conforme destacado anteriormente como objeto de estudo deste trabalho.

\section{Tabela 3 - Modos de controle do sistema}

\begin{tabular}{|c|c|}
\hline $\begin{array}{c}\text { Tipo de } \\
\text { acionamento }\end{array}$ & Sistemas \\
\hline $\begin{array}{c}\text { Sistemas com } \\
\text { controle } \\
\text { manual }\end{array}$ & $\begin{array}{l}\text { - Manual on/off near the door } \\
\text { - Switch off occupancy sensor } \\
\text { - } \quad \text { Photosensor controlled } \\
\text { dimming system } \\
\text { - Combination switch off } \\
\text { occupancy and dimming } \\
\text { system }\end{array}$ \\
\hline $\begin{array}{c}\text { Sistemas } \\
\text { automatizados }\end{array}$ & $\begin{array}{l}\text { - Switch on/off occupancy } \\
\text { sensor } \\
\text { - Combination switch on/off } \\
\text { occupancy and dimming } \\
\text { system }\end{array}$ \\
\hline
\end{tabular}

Assim, o modelo switch off occupancy sensor foi escolhido para representar o grupo de acionamento manual, denominado neste estudo sensor-usuário. Este modelo simula uma rotina de acionamento $\mathrm{e}$ desligamento considerando o comportamento do usuário e um modelo de ativação do tipo on/off.

No grupo de sistemas automatizados, o modelo switch on/off occupancy sensor foi descartado uma vez que é acionado somente de acordo com a ocupação, desconsiderando os níveis de iluminância internos. Assim, o modelo selecionado foi 0

combination switch on/off occupancy and dimming system, denominado neste estudo como sensor-automatizado. Apesar de este modelo possuir um reator dimerizável, foi escolhido uma vez que considera o nível de iluminância do ambiente enquanto o outro modelo considera apenas a ocupação. Este modelo considera uma automatização do sistema por fotosensor e por ocupação, ou seja, a iluminação é acionada quando o ambiente está ocupado e o nível de iluminância está abaixo do pré-determinado. Com intuito de aproximar este tipo de acionamento à realidade de edificações residenciais, foi estimado um sistema de ativação on/off a partir dos resultados do sistema dimerizável. Assim, quando o sistema dimerizável apresentou indicativo de acionamento foi considerado o acionamento total (100\% do fornecimento de luz) do sistema de iluminação.

\subsection{Dimensionamento dos dispositivos}

A tabela 3 mostra o dimensionamento dos dispositivos externos que não venezianas. No geral, PTI/PTF apresentaram os maiores dimensionamentos, seguido do modelo TN, ao passo que o modelo L23 apresentou os menores dimensionamentos.

Tabela 3 - Dimensionamento dos dispositivos tipo brise

\begin{tabular}{c|c|c|c|c|c|c|c|c|c|c|c|c}
\hline & \multicolumn{3}{|c|}{ Norte } & \multicolumn{3}{c|}{ Sul } & \multicolumn{3}{c|}{ Leste } & \multicolumn{3}{c|}{ Oeste } \\
\cline { 2 - 14 } & PTF/PTI & L23 & TN & PTF/PTI & L23 & TN & PTF/PTI & L23 & TN & PTF/PTI & L23 & TN \\
\hline$\alpha$ & $59.9^{\circ}$ & $51.1^{\circ}$ & - & $16.1^{\circ}$ & $51.1^{\circ}$ & - & $78.7^{\circ}$ & $45.0^{\circ}$ & - & $78.7^{\circ}$ & $45.0^{\circ}$ & $75.0^{\circ}$ \\
\hline$\beta \mathrm{d}$ & $44.1^{\circ}$ & - & - & $9.2^{\circ}$ & - & - & - & - & - & - & - & - \\
\hline$\beta \mathrm{e}$ & $44.1^{\circ}$ & - & - & $9.2^{\circ}$ & - & - & - & - & - & - & - & - \\
\hline
\end{tabular}




\begin{tabular}{c|c|c|c|c|c|c|c|c|c|c|c|c}
$\gamma \mathrm{d}$ & - & $45.0^{\circ}$ & - & - & $45.0^{\circ}$ & - & $15.8^{\circ}$ & $51.1^{\circ}$ & - & $72.8^{\circ}$ & $23.5^{\circ}$ & $30.0^{\circ}$ \\
\hline$\gamma \mathrm{e}$ & - & $45.0^{\circ}$ & - & - & $45.0^{\circ}$ & - & $72.8^{\circ}$ & $51.1^{\circ}$ & - & $15.8^{\circ}$ & $23.5^{\circ}$ & $30.0^{\circ}$ \\
\hline
\end{tabular}

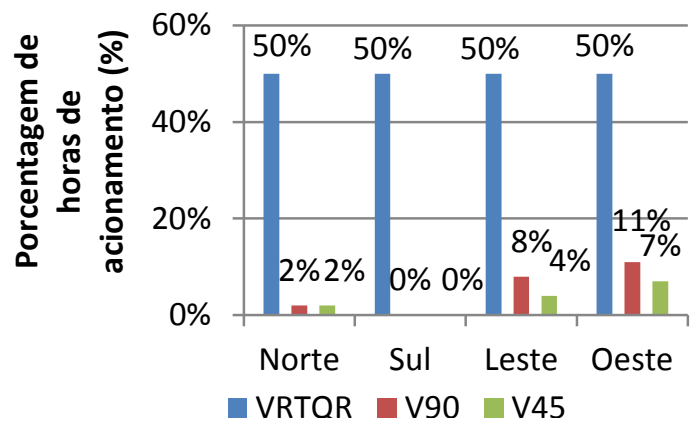

Figura 3 - Acionamento das venezianas

A figura 3 mostra a porcentagem horas de acionamento das venezianas em relação às horas de ocupação do ambiente. Neste caso, observa-se que o maior número de horas de acionamento ocorre para o dispositivo VRTQR. As outras venezianas, V45 e V90, apresentaram poucas horas de acionamento. Estes resultados podem ser justificados pelo fato de o sensor de acionamento das venezianas estar localizado junto ao sensor de acionamento das luminárias, logo, longe da abertura. Portanto, o sensor foi pouco atingido pela insolação direta e brilhos excessivos.

\subsection{Resultados das simulações}

A tabela 4 mostra, para a orientação norte, a variação da porcentagem de horas de acionamento e consumo de energia da iluminação artificial por tipo de dispositivo de proteção e modelo de acionamento. Nas demais orientações foram notadas as mesmas características. Esses gráficos são uma compilação dos resultados de ambientes de estar e de dormitório. Vale destacar que, para os ambientes de estar, foi considerado apenas o sensor mais distante da abertura para iluminação natural para a análise de acionamento da iluminação artificial, a fim de se investigar a necessidade de acionamento no ambiente como um todo.

Tabela 4 - Comparativo do consumo de energia e acionamento da iluminação artificial para o sensor-usuário e o sensor-automatizado, para a fachada norte

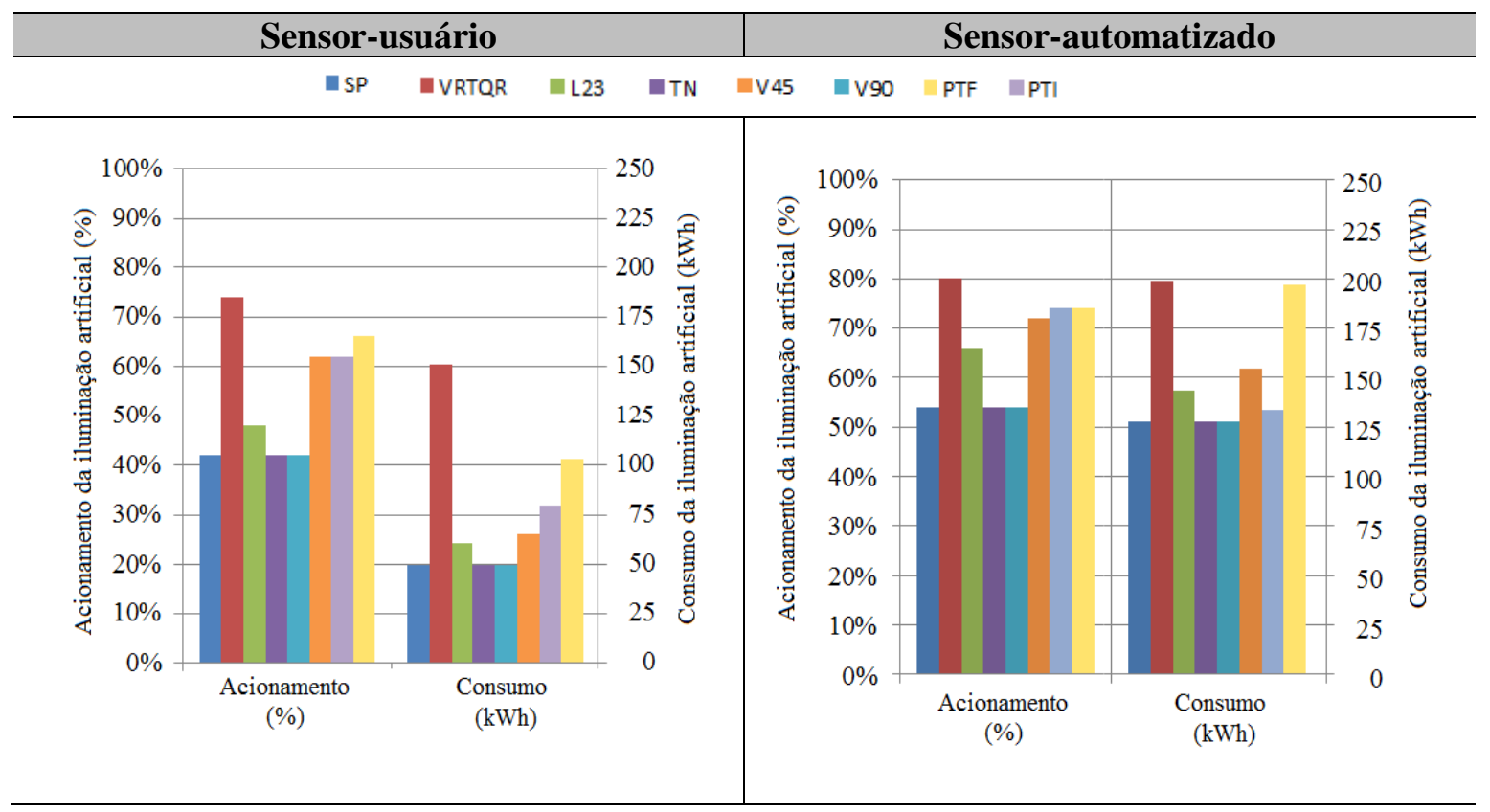

Ao observar os desempenhos dos dispositivos observa-se que os modelos que apresentam dimensionamentos mais robustos, como PTI, PTF e VRTQR, provocam maior escurecimento no ambiente e, consequentemente, maior acionamento iluminação 
artificial. O modelo V45 apresenta mais horas de acionamento da iluminação que a V90, uma vez que uma das folhas da veneziana é fixa contribuindo para um maior escurecimento do ambiente. Ainda de acordo com a Tabela 4, comparando os modelos de acionamento entre si observa-se que o sensor-usuário gerou maior acionamento da iluminação artificial, bem como maior consumo que o sensor-automatizado. Porém, em relação ao modelo sem proteção, o aumento do consumo de energia gerado pelo uso dos dispositivos de proteção solar para cada um dos modelos de acionamento nem sempre foi maior para o sensor-usuário. Tal fato pode ser constado pela Tabela 5.

Tabela 5 - Comparativo entre o sensor-usuário e o sensor-automatizado relativo ao aumento do consumo de energia em relação ao modelo sem proteção nos modelos com dispositivos de proteção solar

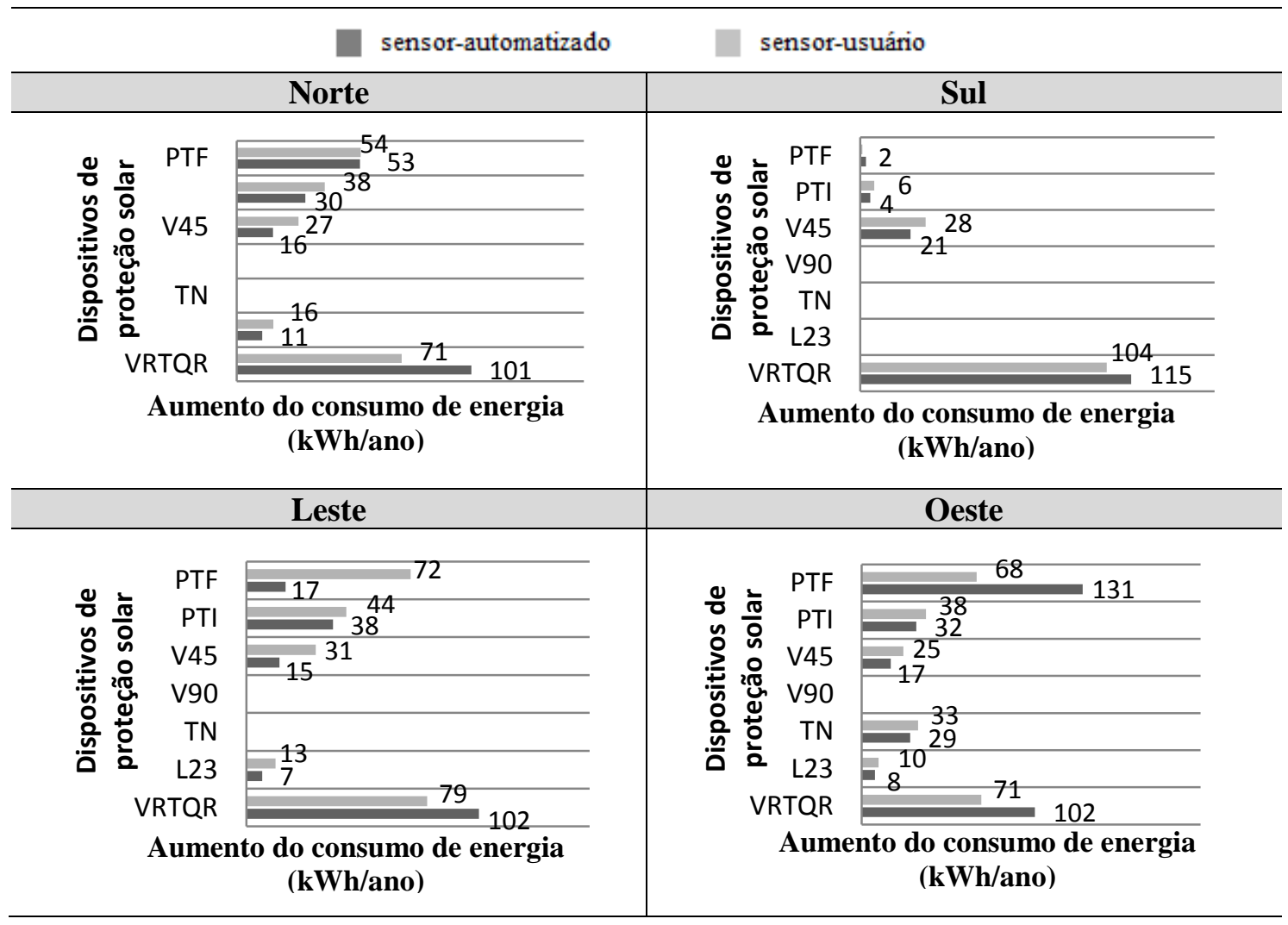

Além disso, pode-se notar uma menor variação do consumo de energia, entre os modelos com diferentes dispositivos de proteção solar, quando a iluminação é acionada pelo sensor-usuário do que quando acionada pelo modelo sensor-automatizado.

\section{CONCLUSÕES E CONSIDERAÇÕES FINAIS}

Neste estudo, foram investigados dois tipos de acionamento da iluminação artificial que puderam ser comparados de acordo com o desempenho apresentado em relação ao consumo de energia: acionamento manual (sensor-usuário) e acionamento automatizado (sensor-automatizado). A partir das análises dos modelos foi possível concluir que o sensor-automatizado representa um usuário idealizado, que aciona a iluminação artificial apenas quando necessário, para o complemento dos níveis de iluminação natural, ao passo que o sensor-usuário retrata uma forma mais aproximada do comportamento de um usuário real.

Os resultados das simulações mostraram que o modelo sensor-usuário consome mais energia que o modelo automatizado. Porém, ao comparar o aumento do consumo de energia nos ambientes com dispositivos de proteção em relação ao modelo sem 
proteção, para cada tipo de acionamento, verificou-se que os valores variaram mais para o sensor-automatizado que para o sensor-usuário. Isso ocorreu uma vez que o sistema automatizado apresenta ativação variável durante o dia, devido ao fotossensor. Esta irregularidade de acionamento resulta em um maior consumo de energia quando comparado ao sensor-usuário, uma vez que o gasto para ativação do sistema supera os gastos previstos de manutenção da luz artificial ativada. Além disso, a ação do usuário no sensor-usuário tende a diminuir a influência do dispositivo de proteção solar na iluminação do ambiente, uma vez que torna o acionamento do sistema artificial mais homogêneo, evitando o consumo de energia relativo à ativação por um maior número de vezes do sistema automatizado.

Ainda assim, recomenda-se utilizar o sensor-automatizado para avaliação do desempenho de ambientes residenciais, uma vez que este permite uma visualização mais precisa da necessidade de acionamento do sistema de iluminação artificial e, portanto, demonstra melhor a influência dos dispositivos de proteção solar na iluminação natural do ambiente. Entende-se que esta pesquisa atendeu ao objetivo de entender o funcionamento dos tipos de acionamento da iluminação artificial do Daysim 3.1, além de mostrar a influência desta escolha para o resultado das simulações.

\section{AGRADECIMENTOS}

As autoras agradecem à Eletrobrás e à FAPEMIG pelo apoio financeiro à realização deste trabalho.

\section{REFERÊNCIAS}

ASSOCIAÇÃO BRASILEIRA DE NORMAS TÉCNICAS. NBR 5413: Iluminância de interiores. Rio de Janeiro, 1992.

BRASIL. Instituto Nacional de Metrologia, Normalização e Qualidade Industrial. Portaria ${ }^{\circ} 1816$ de janeiro de 2012. Regulamento Técnico da Qualidade - RTQ para o Nível de Eficiência Energética de Edificações Residenciais (RTQ-R). Rio de Janeiro, 2012. Disponível em: <www.inmetro.gov.br/legislacao/rtac/pdf/RTAC001627.pdf> Acesso em: Março de 2013.

BOGO, A.J; PEREIRA, F.O.R; CLARO A. Controle solar e admissão de luz natural em aberturas com proteção solar. In: Encontro Nacional de Conforto no Ambiente ConstruídoENCAC, 10, 2009. Natal. Anais ANTAC. Natal, RN, 2009.

CINTRA, M.S. Arquitetura e luz natural: a influência da profundidade de ambientes em edificacões residenciais. Dissertação (Arquitetura e Urbanismo), Universidade de Brasília, Brasília, DF, 2011.

CORBELLA,O.; YANNAS, S. Em busca de uma arquitetura sustentável para os trópicos conforto ambiental. Rio de Janeiro: Revan, 2003, 287p.

GUEDES, A.F.; Análise da iluminação natural a partir do "Regulamento Técnico da Qualidade para Eficiência Energética de Edifícios Residenciais": simulação em edifícios multifamiliares de Belo Horizonte. Dissertação. Escola de Arquitetura e Design, Universidade Federal de Minas Gerais, Belo Horizonte, MG, 2012.

REINHART, C.F.; Lightswitch-2002: a model for manual and automated control of electric lighting and blinds. Solar energy. 2004.

ROAF, S.; CRICHTON, D.; NICOL, F. A adaptação de edificações e cidades às mudanças climáticas: Um guia de sobrevivência para o século XXI. 1. Ed. Porto Alegre, RS: Bookman, 2009.

SOARES, C.P.S.; Investigação do potencial de economia de energia com o uso de dispositivos de proteção solar no Regulamento Técnico da Qualidade para o Nível de Eficiência Energética de Edificações Residenciais. Dissertação. Escola de Arquitetura e Design, Universidade Federal de Minas Gerais, Belo Horizonte, MG, 2014. 